\title{
LOS ALFAQUIÉS DEL OBISPADO DE ORIHUELA EN 1587
}

\author{
por \\ JOAQUIN MARTINEZ VALLS
}

Para poder analizar con objetividad los hechos, no hay que olvidar que en aquella época todos los estados se declaraban confesionales y religiosamente intolerantes con las religiones distintas de la "oficial» o del estado. La unidad religiosa era considerada como la fuerza aglutinante más fuerte de la unidad nacional. No es de extranar la preocupación y el celo de Felipe II por consolidar esa unidad religiosa y su preocupación por el problema morisco. García Villoslada escribe: "Una "quinta columna" - y casi una nación compacta y aíslada, con lengua, usos y religión propia - dentro del estado español la constituían los moriscos (antiguos mudéjares), que, conservando en secreto su religión musulmana, conspiraban con los turcos, con los bereberes de Africa y aun con los hugonotes de Francia" (1). También Reglá había escrito: "La documentación oficial de la época pone constantemente de relieve que Felipe II y las autoridades españolas consideraron a los moriscos como una especie de "quinta columna", que desde sus reductos peninsulares secundaba la presión otomana en el Mediterráneo y la de los hugonotes franceses en el ámbito pirenaicon (2).

No hemos de olvidar que en aquellos años el reino de Valencia conoce una época de enorme inquietud social, con violentas represiones del virev, conde de Aytona, mejorando algo la situación hacia el año 1587. La instrucción clandestina es un elemento clave para comprender cómo las comunidades moriscas se mantenían en su fe y tradiciones, especialmente en el reino de Valencia, que también conservaban la lengua árabe, ya desaparecida entre los moriscos castellanos. Los alfaquíes, expertos en el Corán y generalmente hombres cultos, mantenían el celo religioso de los moriscos; la represión fue en ocasiones particularmente dura con ellos (3). De aquí la preocupación de Felipe II por controlarlos.

En cierto archivo hemos encontrado la carta que Felipe II envía al arzobispo

(1) GARCIA-VILLOSLADA, "Felipe II y la Contrareforma Católica», en Historia de la Iglesia en España, Ill-2. ", BAC (Mạdrid, 1980), p. 36 .

12) REGLA, J., "Estudios sobre los moriscos" (Valencia, 1971), pp. 143.

(3) Véase el documentado trabajo de BENITEZ SANCHEZ-BLANCO, R. y CISCAR PALLARES, E., "La Iglesia ante la conversión y expulsión de los moriscosn, en Historia de la Iglessia en España, IV, BAC (Madrid, 1979), pp. 255-302. 
patriarca de Valencia, obispos de Segorbe y Tortosa $(4)$ y cabildo de Orihuela. La reproducimos a continuación.

Carta que el rey envfa al patriarca y a los obispos de Segorbe, Tortosa y cabildo de la iglesia de Orihuela, sede vacante(5).

«Reverendo en Christo padre Obispo de mi consejo: Después que os scrivi lo que se me offrecia sobre la instrucción de los moriscos de esse Reyno, he entendido que ay entre ellos algunos (aunque pocos) que podrian desayudar, $y$ impedir la doctrina, y pareciendome esto de consideracion, y que obliga a mirar en el remedio, os lo he qüerido advertir para que diestramente y como de vuestro, os informeis quienes son estos y que modo de proceder tienen entre los otros moriscos, y que haziendas para avisarmelo, notando en la relacion que me embiaredes los que fueren casados, y si tienen hijos y cuantos, y de que lugares son vezinos con lo que cerca desto os pareciere que se padria prevenir, y proveer para que no embaraçen ni impidan lo que se pretende, pues siendo pocos seria justo desviallos de los demas.

„En los lugares de vuestra diocesis donde no huviere Iglesias convendra deis orden que luego se hagan por el que en esse Reyno se han acostumbrado hazer, y que se reedifiquen las que estuvieren caidas y maltratadas proveyendolas de ornamentos $y$ los demas necessario al culto divino, encaminando que esto sea sin carga ni molestia de los dichos moriscos, para que no parezca que su doctrina comiença agraviandolos con gastos sino antes que se tiene cuidado de aliviarlos dellos, y con buenos medios y exemplo procurarlos atraer a devocion, $y$ al aprovechamiento de sus almas que es lo que se pretende. de Madrid nueve de julio 1587. Yo el Rey. MatheoVazquez."

El cabildo fue diligente para completar los datos que se le pedian, y poco después envía a Felipe Il la carta que sigue, con el memorial correspondiente a los alfaquíes de la diócesis. Dicen textualmente y. es el original:

$$
\begin{aligned}
& \text { "A la S. C. R. M. del Rey } \\
& \text { don Phelipe nuestro Señor }
\end{aligned}
$$

S. C. R. M.

Con esta embiamos a Vuestra Magestad un memorial de lo que se a podido sacar en limpio acerca de los Alfaquis que puede haver entre los moriscos deste Obispado y por el vera Vuestra Magestad que por nuestra parte se an hecho las diligencias possibles para la averiguacion desto y juntamente por obedescer al mandamiento de Vuedstra Magestad no faltaremos un punto con todas nuestras fuerças. Guarde y prospere nuestro Señor la S. C.R. persona de Vuestra Magestad como estos sus humildes vassallos y capellanes desseamos. De Orihuela y en este cabildo a 30 de agosto 1587.

S. C. R. M. llanes.

Besamos a Vuestra Magestad sus reales manos, sus humildes vassallos y Cape-

El Paborde y Cabildo de la Iglesia de Origuela

14) Se envia al Obispo de Tortosa porque este Obispado tenía gran territorio en el Reino de Valencia. Sobre Geografía Eclesiástica en España véase el amplio trabajo de MANSILLA, D. con el mismo epígrafe en Diccionario de Historia Eclesiástica de Espaxa, $l$ (Madrid, 1972i, pp. 983.1015.

(5) Se envía al Cabildo porque la Sede estaba vacante por muerte del Obispo D. Tomás Dassio Albats el 19 de mayo de 1585 y que fue el segundo Obispo de la Diócesis. Y aunque poco después Felipe Il proponía como Obispo a D. Pedro de Aragón, Canónigo dignidad de Zaragoza, nunca llegó a tomar posesión de la Diócesis, que estuvo de hecho vacante hasta el 26 de febrero de 1588, en que tomó posesión el tercer Obispo D. Cristobal Robuster de Samant. Cfr. VIDAL TUR, G., «Un Obispado español. El de Orihuela-Alicante), I (Alicante, 1962). 
El doctor Johan Baptista Monllor
El doctor Hieronymo de Aracil

"Memorial del Cabildo de Origuela acerca de los Alfaquis del Obispado.

Hechas las possibles diligencias segun el orden que Vuestra Magestad no a dado hemos sacado en limpio que en todo este Obispado no ay Alfaqui entre los moriscos que publicamente enseñe ni se tenga por tal por miedo que tienen al Santo Officio, pero ay algunos sospechosos en el officio de Alfaquis, que son los siguientes

\section{Albatera}

En el lugar de Albatera que es de D. Ramon de Rocafull ay un morisco llamado Luis Sabala que es sindico de la aljama de edad de sesenta años sabe leer y escrevir Arabigo tiene de hazienda hasta en quatro mil ducados, es casado tiene dos hijos respectan los moriscos y es hombre sospechoso en la secta de Mahoma $y$ en ser Alfaqui.

Francisco Alazon de edad de quarenta años lee y escrive Aravigo y dizen es muy mal inclinado y muy amigo de la secta de Mahoma tiene hazienda hasta seys mil ducados.

Tambien ay otros tres que saben leer y escrevir Aravigo aunque no con sospecha de Alfaquis.

\section{Crevillente}

En el lugar de Crevillente que es del Duque de Maqueda ay uno llamado Joan Alehidiçi que es sindico de la Aljamá es de edad de ochenta años viudo tiene solo un hijo y poca hazienda no ay señal de que sea Alfaqui mas de que lleva las quentas del lugar en aravigo vque el cargo de sindico es sospechoso.

\section{Raval de Elche}

En el Raval de Elche que es del Duque de Maqueda ay dos sindicos el principal se llama Francisco Bençuar de edad de sesenta años tiene tres hijos lee y escrive aravigo vale su hazienda mas de qatro mil ducados.

El otro sindico se llama Luis Bençuar de edad de setenta años lee y scrive aravigo tiene dos hijos y mas de dos mil dúcados de hazienda.

Demas de estos ay doze moriscos que saben leer y screvir Aravigo.

\section{Aspe}

En el lugar de Aspe que es del Duque de Maqueda ay un sindico llamado Luis Mascom de hedad de sesenta años vale su hazienda syscientos ducados es viudo $y \sin$ hijos lee y scrive aravigo..

Ay otros que saben leer y escrevir aravigo y algunos moçcos que aprenden agora y ay dos entre ellos moros famosos el uno llamado Ramoni Berberus tenido por grande Alfaqui y el otro Joan Alfafor tenido por grande moro.

\section{Novelda}

En Novelda que agora possee el marques de Terranova ay un morisco famoso llamado Lorenco Bellub viudo de edad de setenta años sindico de la Aljama lee y scrive aravigo y le respectan mucho todos los moriscos de la comarca y dizen enseña a leer y escrevir Aravigo y nos ha hecho relacion el cura de Novelda que todos lo tienen 
por principal Alfaquin y muy perito en la secta de Mahoma tiene de hazienda como mil ducados y quatro hijos y tres hijas todos casados $y$ ricos.

Hay tambien en Novelda un hierno de dicho Lorenco Bellub llamado Baltasar Garcia escrive y lee aravigo de edad de cincuenta años vale su hazxienda mas de ocho mil ducados, es tenido por muy abil en la secta de Mahoma, se sospecha que es Alfaqui y gusta de ospedar los cautivos moros de berberia y favorescerlos tiene un hijo de edad de treynta años $y$ rico.

Luis Mascom de edad de cincuenta y cinco años lee y scrive aravigo es muy experto en la secta de Mahoma y se sospecha ser Alfaqui ospeda a los moros cautivos berberiscos de buena gana es casado tiene un hijo y dos hijas vale su hazienda mil y quatercientos ducados.

Pedro Benda de edad de sesenta años lee y scrive aravigo y se presume ser Alfaqui este caso con una granadina al parescer buena cristiana y el marido la pervirtio a ella y a un ermano suyo tiene el dicho Benda dos hijos vale su hazienda mas de mil ducados.

Sin estos ay otros doze que saben leer y screvir aravigo sin dellos mala sospecha de Alfaquis.

\section{Monnovar}

En Monnovar ques de doña Margarita de Borja ay un morisco llamado Guillom Pedras de hedad de cinquenta años tiene dos hijos y tres hijas vale su hazienda seyscientos ducados lee y scrive aravigo esta sospechoso de ser Alfaqui.

Joan Corroy es moço, por casar de edad de veynte y dos años descendiente de Alfaquis a sido Collegial en Valencia en el Collegio de los moriscos y bino de ella con muestras de buen christiano y aqui se a pervertido lee y scrive Aravigo.

Luis Albiari de edad de quarenta y seys años tiene dos hijas y quatrocientos ducados de hazienda lee y scrive aravigo y enseña a leer y screvir aravigo y se tiene por muy platico en la secta de Mahoma.

Y sin los dichos ay en el mismo lugar mas de ciento que saben leer y screvir aravigo.

\section{Elda}

El Elda quie es del Conde delda esta un Baltasar Milich descendiente de Alfaquis de edad de quarenta años con mil ducados de hazienda es casado y tiene un hijo $y$ tres hijas es sindico dellos lee y scrive Aravigo y sin sospecha de Alfaquin.

Joseph Alasmar de nacion berberisco que fue cautivo andando cossari y se baptzo en Alicante y le conoscieron por nieto de un grande Alfaqui de Elda+y este dicho Joseph Alasmar esta casado alli es de edad de quarenta y cinco años tiene poca hazienda sabe leer y screvir aravigo desde se sospecha que enseña la secta de Mahoma.

Muchos otros ay que no tienen esta sospecha aunque saberi leer y screvir aravigo.

\section{Petrel}

En Petrel que es del Conde de Elda ay algunos sospechosos de que sustentan en aquel lugar la secta de Mahoma el primero es Joan Lopo sindico de la Aljama de edad de cinquenta y cinco años Es casado tiene seys hijos y tres hijas vale su hazienda dos mil $y$ quinientos ducados, lee y scrive aravigo. 
Joan Panchut de edad de treinta $y$ ocho años es casado tiene tres hijos y tres hijas vale su hazienda quatro mil ducados lee $y$ scrive aravigo.

Francisco Duçalem de edad de quarenta años es casado tiene dos hijos y quatro hijas vale su hazienda dos mil quinientos ducados lee $y$ scrive aravigo.

Alonso Alayson de edad de cinquentá y cinco años es casado y tiene una hija vale poco su hazienda y a dieciocho años que esta ciego y muestra ser muy aficionado a la sectas de Mahoma y sospechoso que la deve confessar. en secreto.

Otros ay que leen y scriven en Aravigo pedro sin sospecha de Alfaquis.

Tenemos relación que todos los que son sindicos en los lugares de moriscos tienen sospecha de ser Alfaquis porque llevan las quentas y repartimientos de las tierras en lengua Araviga y con esta occasion accuden todos a sus casas y los respectan y honrran mucho. Pero no constando legitimamente de que sean Alfaquis ni haver otra prueva mas que la suspicion peresce que por agora no deven ser hechados de sus tierras assi por el notable daño que recibirian en sus personas y haziendas como por el alteracion que podria esto causar en todos los demas y la nueva indignacion que cobrarian contra los christianos.

$Y$ ansi los remedios que parescen mas acomodados para la buena direccion de esta obra podrian ser estos

Que se les mande luego a los susodichos que se trasladen los libros de las quentas y repartimientos en nuestra lengua dentro de un cierto termino y que no puedan leer ni screvir Aravigo ni tener ningun libro en lengua araviga.

Tambien paresce que seria de mucha importancia quando se haya de comencar esta obra mande Su Magestad que de su parte y en su real nombre sean llamados todos los susodichos sospechosos ante algunas personas graves y con blandura se les diga y encargue que ellos ayuden a esta obra dandoles a entender que podran ser mucha parte para ello por ser sindicos $y$ tenidos en opinion entre los demas moriscos con apercibimiento que si la dicha obra no tuviese buen successo se entendera quie ellos son los que la estorban y impiden y entonces se procedera contra ellos con todo rigor y este remedio se cree que sera de grande effcto y que aplicado en los principios no podra dañar sino aprovechar y en el discurso si conviene se podran aplicar otros mas rigurosos."

(En otro folio se lee: Memorial del Cabildo de Orihuela acerca de los Alfaquis del Obispadol.

Queremos terminar este breve trabajo resaltando dos aspectos que se deducen del Memorial del Cabildo. Primero, la exquisita prudencia del Cabildo, diciendo que no deben ser castigados porque no hay otra prueba de que sean Alfaquies «más que la suspición".

En segundo lugar, un estudio demográfico sobre los datos que aporta este interesante y detallado Memorial. Vamos a excluir en el cómputo al Alfaqui casado sin hijos, y al soltero, pues dada la costumbre entre los morìscos, costumbre que perdura aun hoy día en muchas partes de los países mediterráneos del norte de Africa, vivirian con otros parientes o familiares. $Y$ el resultado del resto es el siguiente:

Uno tiene nueve hijos, indice 11.

Uno tiene siete hijos, índice 9.

Dos tienen seis hijos, índice 8.

Uno tiene cinco hijos, índice 7. 
Uno tiene cuatro hijos, indice 6.

Dos tienen tres hijos, índice 5

Dos tienen dos hijos, índice 4.

Uno tiene un hijo, índice 3.

Vemos, por tanto, que el índice por familia era bastante elevado. Lo cual nos confirma en nuestra opinión, que ya hemos expuesto en otros trabajos, de que el índice por fuegos o casas para los moriscos, al menos de esta región, debe ser el de 6 (6).

GARCIA CARCEL R. escribe:

"Asi, pues el coeficiente demográfico (número de habitantes por fuego), tan debatido, quizás haya que rebajarlo. En Cuenca, el coeficiente propuesto por M. Garcia Arenal es del 3,6; para Granada, tanto Ruiz Martín como Vicent aportan el coeficiente 4. Para Valencia, nos inclinamos por esta cifra, desde luego por debajo de las establecidas por $\mathrm{H}$. Lapeyre $(4,5)$ y $\mathrm{J}$. Reglá $(5)$. El mayor diferencialismo del régimen demográfico morisco respecto al cristiano radicó evidentemente en la trascendencia dada al linaje y en la concepción mucho más libre y desprejuiciada del matrimonio" (7).

Con todo el respeto que nos merece el eminente investigador profesor García Cárcel, hemos de manifestar nuestra disconformidad con su opinión.

Quizá la confusión estribe en equiparar fuegos o casas a familia, o sea, pensar que en cada fuego vive una sola familia, padres e hijos. Pero aún así, el índice, según la estadistica de los Alfaquies que se contiene en el Memorial del Cabildo de Orihuela, es superior a la comúnmente admitida, y es casi de seis. No podemos aplicar los esquemas familiares cristianos a los moriscos. A esto hemos de añadir la observación que el obispo de Orihuela, don José Esteve Juan, hace en la Relación de la Visita "ad limina" enviada al papa en 1601 y que hemos publicado (8). Constata el mentado obispo: tare».

"Est enim moris huius gentis plerosque de familia et genere eadem in domo habi-

Si esto lo afirma el obispo es. porque le llama poderosamente la atención, y es algo distinto de lo que ocurre entre los cristianos viejos. O sea, que en la misma casa viven, no sólo la familia en el sentido de padres e hijos, sino también parientes, como pueden ser los abuelos, tíos solteros, o el hijo recién casado, etc. Además, el susodicho obispo habla de los que comulgan, dice que "son más de doce mil" entre los moriscos. Es decir, está aplicando el índice 4 sólo para los que comulgan. Y hemos de tener muy presente que en aquella época se empezaba a recibir la Eucaristía hacia los catorce años. Contemos. Además los viejos, y otros, que por diversas razones no comulgan, así como los niños que no tenían costumbre de hacerlo, ni siquiera entre los cristianos viejos.

La conclusión, por tanto, en base al Memorial y a las razones fundadas en la información del Obispo Esteve, es que el índice para los moriscos, al menos de esta región o diócesis, debe ser de seis.

(6) MARTÍNEZ VALLS, J., "Los moriscos de la Diócesis de Orihuela a finales del $s$. XVl y legislación particular canónica sobre los mismos», en Anales de la Universidad de Alicante, Facultad de Derecho, 1 (1982), pp. 243-272. Y "Las primeras relaciones y visitas "ad limina" de la Diócesis de Orihuelan, en Studia Historica in honorem Vicente Martinez Morella (Alicante, 1985i, pp. 269-300.

(7) GARCIA CARCEL, R., "Herejía y Sociedad en el s. XVI. La Inquisición en Valencia, 1530-1609" (Barcelona, 1980). p. 227. y REGLA, J., en «Estudios sobre los moriscosn. Anales de la Universidad de Valencia, curso 1963-64, XXXVII, p. 169. que amplía el índice 5 .

(8) El texto integro de ba Relación puede verse en MARTINEZ VALLS, J., "Semblanza biográfica del Obispo de Orihuela Don José Esteve Juan (1551-1603) y sus relaciones "ad limina" ", en Anthologica Annua (Roma, 1980), pp. 555-612, y en el trabajo "Las primeras relaciones..." antes citado, en la p. 296 en cuanto a la frase en cuestión. 
Este modesto trabajo quiere ser un ferviente y cálido homenaje al eminente catedrático de Derecho Canónico de la Universidad de Murcia, doctor don Mariano López Alarcón, con motivo de su jubilación. 